\title{
How to Begin, Again. Relational Embodiment in Time Arts \& Anthropology
}

\author{
Anne-Sophie Reichert ${ }^{1}$ \\ University of Chicago, Illinois, USA
}

\begin{abstract}
This paper proceeds from ethnographic fieldwork with the Chicago-based performance art group Every house has a door. I analyse the performer's aim to engage with the past in a sensuous and embodied manner and I discuss the practice of cross-temporal collective relationality, which challenges notions of embodiment as being limited to an individual "body proper" (Farquhar/Lock 2007). While forms of relationality are central to artistic research and performance, I remain critical of their immediate political potential. I explicate this argument by discussing Every house's practice with respect to contributions in relational aesthetics (Bourriaud 1997, Bishop 2004). Emerging out of my critical engagement with Bourriaud, I propose an understanding of relationality which is neither built on individual personhood nor immediately politically desirable. Instead, and emerging from fieldwork with Every house, I suggest that embodied relationality can be understood as foregoing individual experience. While this kind of relationality can be emancipatory, its normativity has to be explained with care.
\end{abstract}

Keywords: embodiment, performance art, relational aesthetics, archive, form

One. 1990. Begin. Again. Can We? Begin Again. One.

Speaking deliberately, Selma Banich opens 9 Beginnings. It is January 24, 2014, $7.42 \mathrm{pm}$ at the Gray Center for Arts \& Inquiry in Hyde Park, Chicago. The Chicago performance art group Every house has a door has just opened tonight's run of their latest work 9 Beginnings:

1 Department of Anthropology. I am deeply indebted to all members of Every house has a door for their hospitality, generosity and critical feedback on this project. Many thanks to Mary Jo Schnell, Chris Sullivan and Robert Metrick for taking time to answer my many questions. Comments from Judith Farquhar, Michael Rossi, participants of the Anthropology Graduate Student Conference "The (Troubled) Field" (NSSR, April 2014) and participants at the Knowledge/Value Workshop (University of Chicago, April 2014) all contributed to earlier versions of this article. Finally, I would like to thank the two anonymous reviewers for their comments, which substantially improved an earlier draft of this paper. Author's contact email: sophiereichert@uchicago.edu. 
Bristol E Chicago. Engaging with the live art archives of the University of Bristol and Arnolfini in the UK, and the Randolph Street Gallery archives at The School of the Art Institute of Chicago, the project restages the beginnings of nine performances by nine different artists or companies in a new arrangement. ${ }^{2}$

Every house's reenactment questions the distinct quality of performance as the ephemeral live art experience par excellence: that which can never be re-presented; that in which you don't play your role, you are your role (Schneider 2011: 125). Rebecca Schneider argues that the "immaterial labor of the performing body" (Schneider 2011: 131) cannot be replaced-it is a living ritual, the "singular spectacle of the body-in-action of the performance artist" (GómezPeña c.f. Schneider 2011: 131). Reenactment then, purposely troubles the alleged singularity of phenomenal experience, of the individual subject, and of original, authentic art. Instead, it sets out to highlight prevailing connections and establish new links between performances and performers. ${ }^{3}$

In early 2014, I was allowed to accompany Every house has a door for a residency at the Gray Center in Chicago, a space for interdisciplinary arts-sciences collaborations at the University of Chicago. My aim was to explore whether the interaction of perception, affection, cognition and body movement could be understood in a way that does not have to presuppose an autonomous individual but conceptualises being as thoroughly social. Ethnographic fieldwork with performers, who are trained to be extremely aware of their bodies and to manipulate affective atmospheres, seemed like a promising start to such an investigation.

The study of body movement can be found at the origins of anthropological inquiry. E. E. Evans-Pritchard argued for dance as a concern for anthropological study (Evans-Pritchard 1928) and Marcel Mauss understood body movement and technique as socially acquired yet non-discursive elements of culture (Mauss 1934). Yet, since the influential collaboration of Victor Turner and Richard Schechner in the 1970s (Schechner 1985, Turner 1986), anthropology has looked at various art forms and music as important elements of culture but has paid comparatively little attention to performance art and dance. I would like to suggest that by coupling the recent anthropological interest in contemporary art (Ingold 2013, Schneider/Wright 2010 and 2013, Foster 1995) with anthropological research on the materiality of the body and

2 Performance and performance art are wide-ranging and contested fields. Using terms like performance art, performance artists and performers in this paper, I refer specifically to contemporary performance art in Western, mostly US-American and European, artistic contexts, which can broadly be understood as a postmodern answer and critique to the formal and stylistic conventions of more classical forms of theatre. Performance arts' origins are often traced to Dada and Futurism in Russia at the beginning of the $20^{\text {th }}$ century, as well as to the thriving experimental arts scene in New York City in the 1960s and 1970s. For an overview about the history and conceptual understandings of performance art see Auslander (1992), Carr (1993), Goldberg (1998), Banes (1998), Jones/ Heathfield (2012).

3 Throughout this paper, experience is not understood as foregoing conceptual abstraction, representation, or discourse, since this would presuppose a kind of authentic substance in which such experience could unfold (cf. Scott 1992). Post-essentialist thought after Foucault often runs the danger of loosing the grip on objects and subjects, which are not solely discursive but equally material, moving, and alive, and which matter precisely with respect to these characteristics. While operating within the realm of "experience" always involves the danger of reaffirming a metaphysics of substance (Povinelli 2014), the category experience nevertheless has two advantages here. First, it is the term with which the performers operate and use to designate their work themselves: their job is to produce meaningful and affective performance experience. Second, it makes it possible, at least momentarily, to fathom and discuss phenomena, which I deem central in the production process of meaning: corporeality, sense perception, body movement, and affective, or emotional relationality. 
embodiment, as well as with recent contributions on the relation of politics and aesthetics in performance studies, political theory and art history (Phelan 1993, Schneider 2011, Kompridis 2014, Ziarek 2012, Bourriaud 1998, Bishop 2004 and 2012), performance emerges as a social field that deserves ethnographic attention. ${ }^{4}$

This paper is divided into four sections. First, I introduce the performers of Every house has a door and their work 9 Beginnings, focusing on the process of reenacting and reimagining performance. Section two proposes three different kinds of relationalities between past and present in performance experience. I observe that collective relationality, which enables performance as a world, is transtemporal, embodied and affective. In section three, I interpret the political potential of Every house's collective practice against the backdrop of relational aesthetics and draw out critical differences between embodied relationality in the practice of Every house, and relational aesthetics after Nicolas Bourriaud. I conclude by sketching how the kind of relational being-in-the-world that emerges from my ethnographic inquiry challenges an understanding of relational art as inherently democratic, yet allows for an understanding of form as normative.

\section{How to Begin}

9 Beginnings started with an invitation to an archive. The University of Bristol and the contemporary arts space Arnolfini invited Lin Hixson, the director of Every house has a door, and Matthew Goulish, the dramaturge of Every house to engage with the Live Art Archives Bristol, the primary archive for contemporary performance art in the UK. Matthew and Lin took up the invitation and spent four weeks in the summer of 2012 in Bristol, digging through an abundant collection of videotaped performances. They selected nine videotaped performances, which were then staged in a performance in Bristol. In summer 2013, Lin and Matthew entered another archive: that of Randolph Street Gallery, a former progressive arts space in Chicago. ${ }^{5}$ Again, they selected nine performances on videotape that were put on stage in Chicago. When I met Lin and Matthew in January 2014 they wanted to bring these two sets of works together, weaving them into one single performance.

Why beginnings? As Hito Steyerl writes in a recent essay on the oeuvre of documentary filmmaker Harun Farocki: "The first sentence sets the scene. It is a building block for a world to emerge in between words, sounds, and images. A good beginning holds a problem in its most basic form. It looks effortless, but rarely is. A good beginning requires the precision and skill to say things simply. Like the crafts of making bricks, weapons, or files on hard drives, there is an art of creating beginnings" (Steyerl 2014). Watching hours of performances on video imagining their potential restaged, Lin and Matthew chose to focus on beginnings precisely because of their ability to hold a world that is still to unfold. Their new beginnings would figure as live archives: a performance re-presenting a former performance.

4 For a recent anthropological engagement with the political potential of performance see Flynn/Tinius (2015), for an overview of the anthropology of performance see Korom (2013), for dance ethnographies see Davida (2011), Buckland (2010), and Royce (2002).

5 Randolph Street Gallery hosted visual art exhibitions, performances, as well as dance performances, and was engaged in community outreach from 1979-1998. Its archive is currently in storage at the School of the Art Institute of Chicago. 
Every house's endeavour is not a meticulous replication of the former works. The production of exact sameness is not desirable for the performers since it presupposes a kind of original body movement that can be copied one-to-one. But it is precisely this idea of original body movement that performers like Every house's and performance theorists like Schneider continually question. To Schneider, "all bodily practice is, like language, always already composed in repetition and repetition is, paradoxically, both the vehicle for sameness and the vehicle for difference or change" (Schneider 2011: 10). Lin affirms that there is no authentic, the authentic is already multiple, made up-part of a tradition, piece of a repertoire. As much as Every house's performance is composed through restoring a past performance, so was exactly that past performance concerned with connecting to other past events, actions, and themes (cf. Schneider 2011: 126-127).

The members of Every house think that they can only live up to what the archival sources demand if they warp them, enacting them in their own variation. Lin explains: "It was taking this material and turning it in such a way that we embodied it. Rather that, than trying to duplicate what we saw." Turning begins with limitation. Performer Nik Wakefield characterises the compositional process of 9 Beginnings as one of subtraction rather than of production, of cutting away in order to reveal what matters. A first constraint was to solely work with beginnings. Another limit, and one that Lin and Matthew understand as central to reenactment, was to focus on the vital qualities of the videotaped performances; a process which Lin calls "capturing the forces". A third restriction was practical possibility. In selecting the videos from the archives as well as in deciding how to exactly reenact certain scenes, it was often a matter of considering what was doable, given the performers, materials, and resources at hand in rehearsal. These practical decisions went hand-in-hand with detecting the emblematic elements of the former works. In one scene, Sebastián reenacts the beginning of Cavalcades in Learning, a performance created by Chris Sullivan and performed in 1989 at Randolph Street Gallery. In his version, Chris Sullivan set up a stage with loose floorboards, which caused him to dodder whenever he walked on it. In Every house's reenactment, there are no loose floorboards, but Sebastián's legs shake tremendously throughout the whole scene. Reenacting the emblematic means to find out what defines a situation instead of solely trying to copy it. Through impersonating the leg movement, "you have the unstable floor although you don't really have it". ${ }^{6}$ Every house understands these choices made in the production of the performance as a collective subjective process. As Selma comments:

Different hosts bring different meaning and a different experience to the body of work. There are different versions or possibilities, or different trajectories that are equally important and equally authentic. [...] You don't really know anyway what is the master tape and what are the copies.

Every house does not claim authoritative exclusivity to their iteration of the performances; to them, it is more important to investigate the practical possibilities for engaging with the archival materials. Doing so, they contribute to the ongoing discussion of how to archive performance while keeping it alive.

6 All following direct speech citations are, if not stated differently, quoted from individual interviews which I conducted personally with Selma Banich, Sebastián Calderón, Annalaura Alifuoco, Nik Wakefield, Lin Hixson and Matthew Goulish between January and June 2014 in Chicago. 


\section{Collective Experience and Sticky Matter}

The world which Every house inhabits is a complicated network of materials, bodies, places, and feelings. This section is concerned with the human relationalities, outlining three different modes that all take connectivity rather than individuality as their starting points. With Marilyn Strathern, I perceive "[b]odies [as] compris[ing] a field of relations" (Strathern 2009: 150), a plane on which that which we might perceive as single skin-bounded individuals are complexly interwoven. Understanding life as thoroughly social, I view humans as being continuously enmeshed in meaningful relations to each other, thus producing shared experiences and common worlds (cf. Haugeland 1982).

The first relation is that of Every house to the former performers and their original works which Every house restages. ${ }^{7}$ This connection has to be established from the present into the past. Starting points are the videotapes from the archives in Bristol and Chicago, which mediate the performers access to the past performances. For Sebastián, a videotape can tell him more than a written script could because it provides a moving image of the performing body:

Think[ing] of the video screen as a script is very interesting to me [...] because it is a different way of reading text from a screen, because you are reading the whole situation, the body, the lighting, how it was taped. You try to capture what the situation is, the ambiance of the moment.

Video facilitates access to the past through recalling experience (cf. Ruby 2000: 54). Discerning the atmosphere of a moment past, a sensible connection to the former performers and works is established; something Schneider calls "the affective stain that passes between bodies and time" (Schneider 2011: 135). Lin recounts:

Yeah, it's fascinating because so much of that did come from the video but then that was only a starting point because once Sebastián and Selma started taking on that material, there was something that I trusted that had to do with the impulse of the initial piece. That somehow we were connected to it. I don't know but that's how I felt about it.

While Lin expresses this connection as already existent in the form of a feeling, the performers have to work hard for establishing a felt relation. They search beyond the videotapes for ways to establish links: online research, books, and archival materials about the former performers and their artistic contexts were more conventional ways of becoming familiar with the works, but there was also a great part of imaginary investigation at play. Reenacting the performance of Chris Sullivan, Sebastián tried to understand the relation between Chris Sullivan, the actual person, and the version that Chris created of himself to address the audience in his performance. Sebastián's goal was to craft a version of himself that was like the version that Chris created of himself in his performance. Sebastián did not try to copy Chris's performance but rather Chris's relation to his performing self. In order to relate to the earlier performances and their performers in a meaningful way and thus bring their force into the present, this force has to be understood bodily, it has to be taken into movement. For the performer Selma, this process goes beyond cognitive understanding:

7 I use the word original with care and a certain reservation since I do not think that the issue of ownership of a performance can be discerned easily. Although the performers whose work got reenacted in 9 Beginnings created the performances, they do not own them. Instead of creating entirely new material they drew on accounts of different authors themselves. Their innovation was to assemble the already existent aspects differently. Richard Schechner and Rebecca Schneider have both problematised the issue of non-original body movement. (Schechner 1985, Schneider 2011). 
You think about it when you watch the video, when you research it. You think about how it was for Simone Forti [a former performer]. What did she think when she was doing it? You can prepare yourself in a way but then you have to let go of all of that and just see what the practice of doing brings. [...] I still think when I move but I think differently. I think from the experience of now, and not from what should, what did I read about her or how it was then.

Understanding the past performances and their performers functions for Every house through recognising their absence and as much as their presence. While affirming the boundary between past and present through acknowledging an "original" and its author, which will be reenacted, the same act troubles this boundary. The contingency unsettles the differentiation of past and present; cross-temporal relationalities determine the understanding of time within the performance. In this case, replication and repetition do not threaten the original but might function as vehicles for temporal exchanges and negotiations (c.f. Schneider 2011: 30-31). For Sebastián, 9 Beginnings aims precisely at questioning the originality and singularity of events, whose stringing together establishes linear progressing time. The original and Every house's reenactment can equally be viewed as two separate works, or as one work that is being extended through time:

It's as if all of these beginnings are like a piece of gum and we are grabbing the gum and we are pulling it.It is still the same piece of gum but now we pull it, maybe we twist it here and so in a way it's different, we are elongating the work in a way but by doing that we are also changing its shape. Yet it's always still connected to that first part.

When a performance event is stretched like gum, beginnings and ends appear only as possible, somewhat arbitrary time markers rather than as determinate events. Interesting here is that the performance exceeds its genre's temporal mode, the present, altering an event of the past in an unexpected manner. ${ }^{8}$

Echoing James Gibson (1979), the philosopher Alva Noë conceptualises performance experience as a small-scale environment, in which that what "we encounter is the meaningful world of our possible action [...] not the physical world" (Noë 2013: 126). ${ }^{9}$ A performance attunes us to our "perceptual being-in-the-world", it makes us aware that our environment is one "whose meaning is always specified relative to us" (Noë 2013: 126). According to Noë, a performance teaches us that we dynamically "enact our environments thanks to our skillful engagement with them" (Noë 2013: 126). In the context of Every bouse's work, Noë's account implies that establishing a world through performance depends on recognising and extending meaningful relations to the past works and their performers, as well as the establishment of meaningful relations in the present. Understanding these relations as a practice, Every house enables a contingent performance world which, as Lin frames it, is made up of "connective tissue" (Hixson 2013: 4).

8 Yet, this statement might become controversial in light of the example of Sebastián's use of the videotapes, where the past informs the presence solely via a representation (video-recorded performance) and not through an immediate human-to-human relation.

9 Gibson has been critiqued for conceptualising environment as an inanimate canvas on which the behaver-perceiver acts. Ingold claims that Gibson understands environment as prior to the assignation of value and meaning by a perceiving subject, thus reaffirming an inanimate world, "furnished with objects" (Ingold 2011: 78). While this critique is justified, neither Noë, the performers, nor I perceive environment as such inanimate canvas. Rather, environment is understood as emerging through the process of building meaningful relations and thus bringing a world into being. 
In this practice, the past is more agentive than one might think. On the cold and snowy nights of Every house's performance showings in January 2014, three of the performers who had created and performed work at Randolph Street Gallery between 1989 and 1998 that was now reenacted by Every house came to the Gray Center. Their impressions of the performances are truly fascinating. The reenactments by Every house functioned for all of them as a sensible entry into the past, (re)invoking excitement, fear, sadness, delight and inspiration. At the time, Mary Jo Schnell was the curator of Randolph Street Gallery and often gave improvised preshow announcements. In 9 Beginnings, Matthew reenacts one of her pre-show announcements, providing an insight into the thriving and progressive performance arts scene in the late 1980s and early 1990s in Chicago. After the show, Mary Jo's eyes glowed as she put her first impressions into words: "It's wonderful that Lin and Matt pulled the material out. It would only sit in a stupid box and be dusty if you didn't do that. You liberate the material from its fate, you give it new direction, and you bring it back!" Mary Jo tells us stories from the days of Randolph Street Gallery: how this evening reminds her of the creative and politically radical forces of that time and evokes the desire to create performance again.

Another guest, Robert Metrick, tells me that he was immensely curious to see how Every house would engage with the performance O Klahoma! or The Farmer in the Astral Plains, which he came up with and had performed by a number of performers, one of them Matthew of Every house, at Randolph Street Gallery in 1998. What fascinates Robert is how the reenactment makes unthought-of encounters possible-retrospectively and in the present-through overlapping kinds of formerly separated works:

How the different events sort of materialised and disappeared—it was kind of ghostly. [...] Moments that could have never happened in the past-now things come together that didn't come together in the past. That was kind of otherworldly. I had no idea who the others were, that were simultaneously with me performing [in Every house's reenactment]. I mean, I had never met them or seen their work. So there was this collaboration that [had ]never [happened before] —Lin and Matthew selected those materials and molded Jennifer [Monson], Yvonne [Meier] and me in collaboration. ${ }^{10}$

By bringing these different works into one conversation, the members of Every house problematise their established singularity. They mould the boundaries of different events and entities, building on existing and establishing new links between different moments in time. In my conversations with Mary Jo and Robert it became apparent that when the members of Every house expands and alters their works, this radically changes their relation to them. This might be the "kind of ghostly" effect that Robert described earlier: the past experiences of Mary Jo and Robert adopt a different present than they would have envisioned possible, partly independent from them, yet never fully defamiliarised. It feels like Every house's work and their own work at the same time, like kin yet like stranger.

A second set of relations is that of Every house's members. Although all performers prepare by themselves for the usually short phase of collective practice with the whole ensemble, it is through collective research and rehearsal that bodily inquiry into the past is practiced together. Here, reenactment is an ongoing appropriation, shared by trying out things together. Through enacting the archival sources collectively, the performers bring into being a live archive that is distinct in its dynamic quality. The possibility for enabling this mode of representing the for-

10 In this part of the performance, two beginnings of former performances, O Klahoma! or The Farmer in the Astral Plains by Robert Metrick (1998) and All Fall Down by Jennifer Monson and Yvonne Meier (1991) are reenacted at the same time, woven into each other. 
merly archived works arises through the act of working and embodying as a collective. None of the individual members of Every house could create the performance experience on their own; all performers are needed at the same time and place, engaging in and sharing the practice of performing.

Working with Every house, there was an unusual openness, respect and care. Empathy did not fall victim to intense concentration. During the rehearsal period, the members of Every bouse spun a world of their own; entering their studio space felt like leaving the everyday. The collectivity they created exerts a special affective force; a force that is plural and not multiple, being more than the sum of their individual agencies. This collective force emerges through their being together in the world, hence creating a meaningful world that comes with its own respective atmosphere. Sebastián calls the energy that animates this atmosphere "richness", materialising out of the relations with the others. Annalaura speaks of that what is shared as "sticky matter", the matter of feeling: "To some extent, you find it is shared. Sometimes, as if by magic, you find that everybody in the room may respond to the same thing. That's the moment of intensity. The moment when the atmosphere intensifies." For both Annalaura and Sebastian, it seems that the collective force of Every house arises through creating and sharing feelings and meaning. The delight of shared force is what drives the practice of performing: it is what makes everybody work extremely hard, yet never grimly determined. The formation and circulation of this force is essential for creating a performance that will be affective, that will move and touch the audience. As a matter of feeling, it is both directed and temporary. It is directed towards each other among the performers and once entering the actual performance it might resonate with the audience as well. Yet it is ephemeral: In order to enable and feel it, the performers have to achieve a heightened presence in the moment - they have to be fully devoted to the performance practice; they are the performance. While the creation of shared force depends tremendously on actually being together in one place at a specific time, the encounters with the original performances and their performers have shown already that collectivity might also be experienced transtemporally. In particular the work with the performances from Randolph Street Gallery led Every house to inquire into the communal spirit and practices of the venue at that time: their community outreach initiatives, their non-profit strategies, and their fight for radical art and political change.

Collective embodied inquiry and the production of collective affective worlds question a phenomenological account of an experiencing self that is bound to an individualised "experience-collecting [...] body proper" (Farquhar/Lock 2007: 2). ${ }^{11}$ In order to grasp the quality of

11 Embodiment is a controversial concept. In using the term, I deliberately avoid referring to one specific theoretical definition. I do so precisely because my inquiry is inductive, trying to attend to one "actual form[s] of lived embodiment in the fields of practice" (Lock/Farquhar 2007: 11) rather than measuring it against a general concept of embodiment. In so doing I account for the circumstance that what might be perceived as a general concept of embodiment emerges precisely through exploring and assembling such specific practices of attending and inquiring. Contra the idea of Quinean representationalism (Quine 1951), I argue that an abstract definition of embodiment always emerges in a specific practice and cannot be dissected from the respective practice without losing explanatory value (c.f. Rouse 2007). While I therefore fall short on a comprehensive definition of the term embodiment, three ideas are nevertheless decisive for my approach to, and use of, the term (cf. Scheper-Hughes/ Lock1987). First, the idea of embodiment opposes the binary opposition of Cartesian dualism and reaffirms the human being as grounded in material physicality. Second, following phenomenological theorists such as MerleauPonty, embodiment is understood as lived experience in the presence; as a sensing, perceiving, feeling, and thinking human being in and co-constituting time and space. Third, the experiential quality of being as outlined in phenomenological approaches does not have to stand solely in contrast to accounts which perceive the human body and embodiment as historically, socially, and culturally contingent formations. On the contrary, I understand 
the performer's collective embodiment and the affective forces it generates, neither a purely phenomenological perspective, which implicitly presupposes a given individual body-self, nor a structuralist perspective, which understands the human body as a historically contingent product of semiotic, cultural, and social order, suffices on its own. The structuralist account would not provide sufficient insight into novel individually differing embodied experience of actual material practices and falls short in explaining how the entanglement of perception, emotion, cognition and bodily movement comes about in detail, e.g. in proprioception or kinaesthetics. A purely phenomenological perspective misses out on the productive relationality and interdependence of the performers and might obscure how a specific socio-cultural and historical context shapes their being-in-the-world. What might be more appropriate, then, is a less oppositional treatment of the respective positions. The research, rehearsal and performance of Every house is a collective practice which arises in a specific context and location and configures responsive bodies in meaningful ways, thereby producing and at the same time relying on experientially grounded, sensing, feeling and moving bodies.

Reenactment as enactment in Every house's work is embodiment in the literal sense. The performers attempt to connect to history by engaging in it bodily, animating the past through and in their own experience. In this process, perception, body movement, emotion and cognition are complexly linked, not just in individual bodies but also in between the performers, who move in relational configurations, share thoughts and feelings, and experience the plural force which arises from their mutual work. Collective embodiment denotes this process of collectively taking-into-the-body and producing a shared meaningful world, a practice that requires individual as well as supra-individual intertwined engagement of perception, emotion and cognition.

There is a third set of relations, that between Every house and its audience. One type is seating. The members of Every house passionately discussed how to organise the seating. Their conversations about chairs, risers, and lines of vision became a daily ritual, taking up good amounts of time in feedback rounds and lunch break conversations. The main issue was that the space where they would show the performance did not have a preconfigured and installed seating concept. Before the first actual showing of the performance, the group set up wooden risers which they specifically built for the shows in the Gray Center-a place in which they would only stage the performance three times. On the night of the premiere I understood for the first time why the seating of the audience mattered so much. While I tended to perceive performers and audience as two separated groups in one place but with different jobs, I now understood that the situation at hand was different: performers and audience contribute collectively to the performance experience. The performance is not solely a transmission of a theme from the stage to the audience but it is a shared experience for which both spatially separated sides are responsible. The performers devote so much time to the conscious and self-reflexive construction of the performance venue because they aim at creating a realm in which a palpably collective experience can materialise. In order for the audience to become enmeshed in this performance experience, it is important that they can see properly. Lin reflects:

I think that we found that it's really important that people can see. It's important to me. So that's always been an issue to me that people can see. Cause I am seeing it in this certain way I want everybody else to

the body and embodiment as locations in which biological and cultural or social perspectives collide in fruitful and productive rather than merely oppositional modes. For selected approaches to embodiment see Mascia-Lees (2011), Lock/Farquhar (2007), Csordas (1994) and Gallagher (2005). 
see it. My god, if they can't see Sebastian's legs it's a whole other thing. It's this precision thing. [...] There is something about the idea of a seated audience; someone is seated and just watching. [But] that's not a passive position! It's an active position, a very active position. That people immediately think that if you are seated, if you are not moving around, that puts the spectator in a passive position. I felt like that it's really important that people are taken care of and are comfortable so that they can go into this state where they can actively be involved and be in the performance $[\ldots]$.

Although the performers can prepare the performance space, they cannot control the performance experience. The atmosphere of each night's show depends to a great extent on the different audiences and their interaction with the performance. Involving the audience actively, the collective disclosing of the past expands beyond the members of Every house in the actual live performance. Every house embraces the fact that a specific performance only exists in the moment of the event, in the now. Performance is a shared experience for performers and spectators alike. In the performance, performers and audience form a collective, which enables the performance together. Attuning themselves to their surroundings via sense perception and proprioception, relating to the fellow spectators and the performers, the involvement of the audience is not just a simple absorption of the experience, followed by a form of conceptual understanding. On the contrary, most of the times it is quite difficult to "understand" performance art, to make sense of it. Actively engaging in performance is not just understanding it within the space of reasons; it involves seeing, hearing, sometimes tasting or touching the performance, feeling bodily and emotional resonances. Through the affective involvement in the event, a community of performers and audience forms. Sticky matter is what draws and holds it together. In this sense, its uniting forces are affective and material, felt and sensed.

\section{Relational Aesthetics and Politics}

To recapitulate: the above-explicated relationalities which form the backbone of Every house's performance art exhibit three main characteristics. First, relations are transtemporal, for example, when Every house extends the videotaped performances into the present or when Robert Metrick's understanding of his own performance changes once he sees it back on stage performed by Every house. Second, relations are bodily and material— they can be sensed, felt and moved. One example for this is the collective embodied inquiry into the past that Every house undertakes. Relations are practiced in tangible environments, involving props and tools to configure space and atmosphere. Third, relations produce and hold a shared affective force that has been expressed as felt delight, intensity, ghostly energy or sticky matter. All of these three characteristics contribute toward generating Every house's world. Due to their sensible and affective nature, these relations offer an entry into the very same world they engender.

At this point, it might be worthwhile to bring in one more approach to relationality for comparison. I would like to think the social relationships that undergird Every house's work in line with what has been termed relational aesthetics after Nicolas Bourriaud (Bourriaud [1997] 2002). Drawing out where Bourriaud's and my ideas for relationality overlap and where they diverge, I intend to further hone a framework of relationality as generative of beings and worlds, and as possibly reluctant to capitalist exploitation. Yet, I suggest that when investigating this latter emancipatory characteristic, the relation of form and content has to be treated with care. 
Echoing Bourriaud in an abridged manner, art is relational if it expands the possibilities and the space for intersubjective relations beyond established systems of interaction that are bound up with the capitalist market system. The idea of a microtopia denotes exactly such a place and moment of interaction - an "arena of exchange" (Bourriaud 2002: 7) that aims at divesting itself from the commodification of social relations in the everyday and the art world. Instead, a microtopia is understood as a space in which collectivity functions as a constitutive element of art practice. Artistic inquiry does not solely envision a kind of utopic future anymore; it now practices utopia in enclosed and temporary microtopias in the present.

A first difference between Bourriaud's and the relational approach, which I develop out of my engagement with Every house, exists with respect to the kind of art under consideration. Where Bourriaud is concerned with fine art, Every house create performance art. Bourriaud focuses on artworks; the artist-audience collaboration is the explicit aim of the artwork. Performance, on the other hand, is more an art practice than a piece of art; it is an action not a thing-hence its ephemerality. While interaction with the audience is crucial to Every house's practice, it is not the single end to the performance. Every bouse deliberately preconfigures the performance environment beforehand in order to create a space that facilitates the maximum possibility for the audience to interact with the performers. However, this kind of hospitality can also be understood as delimiting the space of possible actions for the audience. ${ }^{12}$ In fact, Every house coordinates how all relations which converge in their project manifest. While the audience might become immersed in the performance, they are not directly involved in defining and shaping the performance. For this, Every house would have to facilitate the audience's direct engagement in decision-making processes, presumably, even before an audience has formed, in the process of rehearsal. Yet in this case, such modes of engagement are not in Every house's interest. An additional difference between Bourriaud and Every house can be found in their treatment of time: Bourriaud's relational art places heavy emphasis on the present as the exclusive temporal mode in which direct democratic relationality can evolve. One does not get to know much about whether relational art's radical potential can survive in memory or can be cultivated as future possibility. In contrast, Every house's practices are comprised of and stored in collective relations that span from past to present-and back.

Nevertheless, Bourriaud's relational aesthetics and the relational embodiment that I understand to guide Every house's practice share a belief in the political possibilities that collectivities enable. Yet, the understanding of how a collective comes into being and takes on meaning might differ.

For Bourriaud, relational art is "an art taking as its theoretical horizon the realm of human interactions and its social context, rather than the assertion of an independent and private symbolic space" (Bourriaud 2002: 5). One problem with this notion of relational art is that its use can be inflationary: all art that evolves around social interaction may practically be understood as relational in the way Bourriaud imagines it. Every house's work, for example, can be encompassed under Bourriaud's definition. Following Bourriaud would not solely mean that a given arts practice is collective, but that its collectivity can provide and practice new, better and

12 This intervention does not have to be understood as restriction. For Claire Bishop, the clear demarcation of context and selection of participants reflects "precisely the act of exclusion that is disavowed by relational art's preference for open-endedness" (Bishop 2004: 72). Yet, following Mouffe and Laclau to whom Bishop refers for her argument, clear demarcation is central to the constitution of a visible and tangible context which can hence perpetuate productive antagonisms, the substance of radical democracy. 
potentially anti-capitalist models to inhabit the world. In this respect, the exclusive focus on relationality and its radical democratic potential might divert from further critical expressions and functions of the practice under investigation.. In the case of 9 Beginnings for example, it would be difficult to address Every house's methodological investigation concerning the archiving and representing of live art.

Relational aesthetics appear not to specify exactly how relationality functions in detail. It does not spell out sufficiently that social norms are what, among others, constitute and govern human behaviour and interaction. A central criterion for relational art after Bourriaud is that the artwork allows "me to enter into dialogue" (Bourriaud 2002: 109). Yet, entering a dialogue successfully depends on knowing and playing "the rules of the game". If I do not know the rules under which the dialogue operates, it is highly unlikely that I will be able to enter it. Especially in the art world, which has a reputation for being extremely difficult to access due to its minute codes and rules, entering into a dialogue with an artwork will not only depend on the normative space of an artwork but will also depend on its context and the social rules that govern it. ${ }^{13}$

The art historian Claire Bishop criticises relational aesthetics for understanding humans as whole subjectivities (Bishop 2004: 79), which then practice, seemingly with little difficulty, inter-subjectivity. In other words, the bottom category of relational aesthetics remains the Enlightenment trope of a free and rational single-body individual. This understanding is contrary to the one I have proposed earlier, namely, one, in which relations are constitutive for the formation of a kind of human that we experience as individual. ${ }^{14} \mathrm{I}$ define Every house's practice as relational because I understand it to exhibit a mode of being-in-the-world that is thoroughly social and thus precedes individual personhood. While Bourriaud strives for having relationality at center, the base constituents of his approach remain single skin-bounded individuals. Collectivity comes in a second step; a phase of active production, and this is the work of art. Bourriaud's reliance on individuals leads to experience as, ultimately, a matter of single subjects in a collective situation: "I see and I perceive. I comment, and I evolve in a unique space and time" (Bourriaud 2002: 6). Whether an artwork is relational or not is therefore only visible from a non-relational, individual standpoint. To this end, I propose that it might be productive to extend Bourriaud's relational aesthetics, coupling it with an understanding of relationality which does not presuppose individual subjectivity as the base unit of a collective situation. Bourriaud himself appears to be inclined to such an understanding when he writes: "So the essence of humankind is purely trans-individual, made up of bonds that link individuals together in social forms which are invariably historical." (Bourriaud 2002: 7). Yet, in his following analyses of several artworks, Bourriaud regresses to characterising individual agency more so than relational forces. And, Bourriaud falls short on providing a comprehensive explanation for the inherent normativity of relationality.

Relational aesthetics offer possibilities for progressive politics on the basis of simplifying the complex relations of aesthetic and normative judgment. Put in other words, the possible relations of form and content are reduced to one fitting configuration: the right form of an artwork provides the right kind of political utterance. While these relations cannot be discussed in

13 On the contrary, Bourriaud believes that artistic practice might be "a space partly protected from the uniformity of behavioral patterns" (Bourriaud 1998: 3).

14 This argument bears rough similarity with a more nuanced criticism that Claire Bishop raises when she writes that „[...] the relations set up by relational aesthetics are not intrinsically democratic, as Bourriaud suggests, since they rest too comfortably within an ideal of subjectivity as whole [...]" (Bishop 2004: 67, emphasis mine). 
depth here, I will begin to clarify how their uncritical treatment becomes problematic if one is to render relational art fruitful for anthropological inquiry. In relational artworks as described by Bourriaud, relationality appears to be the form of the art practice and its subject matter at the same time. This conflation of form and content allows Bourriaud simultaneously "to equate aesthetic judgment with an ethicopolitical judgment of the relationships produced by a work of art" (Bishop 2004: 65). It does so because the form of the artwork, relationality, is inevitably understood as inherently normative, in this example, as providing critique and alternative to commodified art and relationships within capitalist life. It does so in contradistinction to a traditional understanding of form as an aesthetic category; of aesthetic judgment as formal judgment. Accordingly, the fact that meaning is elaborated collectively in microtopias renders them automatically politically good or democratic, without specifying their intentions (Bishop 2004: 54). Therefore, Bishop has raised the question how to evaluate of the normativity, in her words, the "quality", of the form microtopia:

When Bourriaud argues that 'encounters are more important than the individuals who compose them,' I sense that this question is (for him) unnecessary; all relations that permit "dialogue" are automatically assumed to be democratic and therefore good. But what does "democracy" really mean in this context? If relational art produces human relations, then the next logical question to ask is what types of relations are being produced, for whom, and why? (Bishop 2004: 65). ${ }^{15}$

Bishop highlights here the point raised earlier: Relationships are governed by norms. She adds two critical issues: relationships are constituted by a specific set of people and to a certain end. Without delving further into the known debate between Bourriaud and Bishop, I would like to make a preliminary suggestion of what anthropology could contribute to this conversation. If anthropology were to engage relational aesthetics, its biggest strength would be that it has a long tradition of analysing social structure and practice, focusing on norms, codes, rules and their reappropriation. Anthropology pays attention to socio-economic and historical contexts, investigating people, places, relations and processes as situated concrete phenomena. Anthropologists might thus be in a privileged position when developing research designs that speak directly to Bishop's most crucial questions: How do we assess or compare relationalities like Every house's? How do we examine the norms that govern the relationships and how do we differentiate such an examination analytically from the goal towards which a collective works?

Yet, if anthropological research is guided by questions like Bishop's, asking for whom, and why which kinds of relations are produced, it remains in a mode of assessing relationality on an individual level. This restriction limits the scope that anthropological inquiry can take. Unlike Bishop, anthropology holds the possibility to develop concepts that emerge from empirical observation and embrace an understanding of human relationality as preceding individuality, thus effectively transcending the mode of individual experience and appraisal.

The anthropologist Roger Sansi has recently provided an anthropological exploration that draws on relational aesthetics. In his research on the collaborative art project Colony at MoMA PS 1 in 2013, Sansi asks, almost exactly in vein with Bishop: "Which protocols do the new

15 Bourriaud has been critical of the idea of relationality for the sake of relationality itself: "The question we might raise today is, connecting people, creating interactive, communicative experience: What for? What does the new kind of contact produce? If you forget the "what for?" I'm afraid you're left with simple Nokia art-producing interpersonal relations for their own sake and never addressing their political aspects" Bourriaud, quoted in Bishop 2004: 68). However, as Bishop shows, several of his examples of relational art appear to fall short on responding to the "what for" question sufficiently. 
collective experiments require?" (Sansi 2014: 156)? In the way it is posed, Sansi's question avoids asking for a cause-and-effect chain that begins with and loops back to individual agency. He instead proposes to think of a collective as a situated experiment that abides to protocols. Although Sansi is sceptical of the emancipatory potential of the art world for society as a whole he relies on Bourriaud's concept of microtopias. Therefore, he ultimately runs into the same problem as Bourriaud when he couples relationality with normativity a priori-without giving an explanation for why relationality as an organising principle is already politically desirable in its own right. The collective experiments that Sansi investigates inside and outside of the art world appear to be progressive and democratic primarily on the basis that they are organised in a relational form. This organisational form can then be infiltrated by other normative agendas, for example, that of the state or that of the market economy. While Sansi does explicate that a collective project can, and does increasingly, comprise several conflicting objectives (Sansi 2014:160), he does not sufficiently explain why the kind of relationality he lays out is, on its own terms, i.e. before it is hijacked by other objectives, ethically or politically desirable. Why is relationality as form already good, even democratic? Why do the organisational structure and the political expression of a collective experiment line up so neatly for both, Bourriaud and Sansi?

\section{How to Begin, Again.}

If we were to presuppose relationality as constitutive of human life worlds, artistic and everyday, and this is what I have been arguing for after analysing Every bouse's relationalities throughout this paper, the political potential of a collective praxis can be discerned on two levels: in its form and in its content. I suggest that it is critical to not conflate these two levels too hastily. Of course, form and content are complexly linked. A specific form, for example, always indicates the origin of the respective content in a given practice. Yet, that does not mean that form and content are the same. If we were to equate the form with the goal toward which a collective works, any group that holds together on the base of embodied and affective relationality would be politically good or desirable. Every house's relational embodiment, the practice of taking archival sources collectively into bodies and reconnecting with other performers and performances through time is an extraordinary achievement of human collaboration. However, I do not think that this act of collaboration automatically holds a kind of radical political potential beyond the transtemporal affective relationalities that it makes felt for the performers and the audience. These relationalities can, obviously, provide a kind of lived empathetic collaboration that appears to be quite rare in a time in which an understanding of humans as atomistic alienated individuals dominates. Yet, we would still have to explain how, and to what end exactly, such a felt collaboration is politically or ethically desirable.

To conclude, I would like to offer one possible explanation for how relational form, and, consequently, a kind of relational aesthetics that does not presuppose self-contained individuality can be understood as exerting normative, and thus potentially politically desirable, force. The anthropologist Anna Lowenhaupt Tsing has recently proposed an answer as to why exactly relationality can be averse to capitalism; an argument that all authors discussed so far herein have not yet provided. Admittedly, Tsing's context is not the art world; but the life world and exchange routes of matsutake mushrooms. What Tsing calls "contaminated diversity" (Lowenhaupt Tsing 2015: 33) are entangled and conflicting forms of identities and histories of 
landscapes and people that, in her story, evolve around the worlds of the matsutake mushroom. This contaminated diversity, so Tsing, is primarily relational:

"[It] has no self-contained units; its units are encounter-based collaborations. Without self-contained units, it is impossible to compute costs and benefits, of functionality, to any "one" involved. [...] Without algorithms based on self-containment, scholars and policymakers might have to learn something about the cultural and natural histories at stake. That takes time, and too much time, perhaps, for those who dream of grasping the world in an equation" (Lowenhaupt Tsing 2015: 33-34).

Echoing Tsing's argument for the purposes of understanding the political potential of relationality in the context of performance art and anthropology proposed here, it becomes apparent that the collective embodiment that I have observed in the small-scale environment of Every house's performance is, in its primarily relational being, something else than the sum of whole subjectivities, or, autonomous individuals. On the contrary, the experience of individually perceiving and feeling beings emerges through collective practice, through making and encountering a specific world of possible action.

If a collective, artistic or everyday, is more than a sum of individualised and thus scalable units, if it is, in Tsing's words, an "encounter-based collaboration" (Lowenhaupt Tsing 2015:33), its translation into capitalist assets appears to prove difficult because capitalism runs best on reliable definitive elements. Performance studies scholars like Schneider have long argued that the ephemerality of time arts is precisely what positions it in opposition to commodified art works that can be hung on walls. It is the non-scalable and always evolving form of relational arts practices which render it reluctant to commodification and possibly recalcitrant to capitalism.

If Anthropology is to engage further with questions of relational encounter, a first step could be to observe under what conditions and protocols collaborative worlds emerge and dissolve. The question of how forms of relationality are bound up with the politics they propose solicits further attention.

\section{References}

Auslander, Philip. 1992. Presence and Resistance: Postmodernism and Cultural Politics in Contemporary American Performance. Ann Arbor: University of Michigan Press.

Banes, Sally. 1998. Subversive Expectations: Performance Art and Paratheater in New York, 197685. Ann Arbor: University of Michigan Press.

Bishop, Claire. 2004. "Antagonism and Relational Aesthetics." In: OCTOBER, no. 110, pp. 51-79.

Bourriaud, Nicolas. 2002. Relational Aesthetics. Dijon: Les Presses du Réel, 2002.

Buckland, Theresa Jill. 2010. "Shifting perspectives on dance ethnography." In: The Routledge dance studies reader. 2d ed. Edited by Alexandra Carter and Janet O'Shea, 335-343. London: Routledge.

Carr, C. 1993. On Edge: Performance at the End of the Twentieth Century. Middletown, CT: Wesleyan University Press.

Csordas, Thomas (ed.). 1994. Embodiment and experience: the existential ground of culture and self. Cambridge, MA: Cambridge University Press. 
Davida, Dena, ed. 2011. Fields in motion: Ethnography in the worlds of dance. Waterloo, ON: Wilfrid Laurier Univ. Press.

Evans-Pritchard, E. E. 1928. The dance. Africa 1, 446-462.

Farquhar, Judith \& Lock, Margaret. 2007. "Introduction.” In: Beyond the Body Proper. Reading the Anthropology of Material Life, edited by Margaret Lock and Judith Farquhar. Durham/ London: Duke University Press.

Foster, Hall. 1995. “ The Artist as Ethnographer?” In: The Traffic in Culture: refiguring Art and Anthropology. Edited by G. Marcus and F. Myers. Berkeley: University of California Press.

Gallagher, Shaun. 2005. How the Body Shapes the Mind. Oxford: Oxford University Press.

Gibson, James J. 1979. The Ecological Approach to Visual Perception. Hillsdale: Lawrence Erlbaum.

Haugeland,John. 1982. "Heidegger on Being a Person.”In: Nồs, Vol. 16, No. 1, A. P. A. Western Division Meetings, 15-26.

Ingold, Tim. 2013. Making: anthropology, archaeology, art and architecture. Oxon/New York: Routledge.

Ingold, Tim. 2011. Being Alive: Essays on Movement, Knowledge, and Description. London: Routledge.

Jones, Amelia \& Heathfield, Adrian (eds.). 2012. Perform, Repeat, Record. Live Art in History. Bristol: Intellect.

Korom, Frank J. (ed.). 2013. The Anthropology of Performance. West-Sussex: Wiley Blackwell.

Lock, Margaret \& Farquhar,Judith (eds.).2007. Beyond the Body Proper. Reading the Anthropology of Material Life, edited by Margaret Lock and Judith Farquhar. Durham/London: Duke University Press.

Lowenhaupt Tsing, Anna. 2015. The Mushroom at the End of the World. Princeton/Oxford: Princeton University Press.

Mascia-Lees, Frances E (ed.).2011. A Companion to the Anthropology of the Body and Embodiment. West-Sussex: Wiley-Blackwell.

McCormack, Derek P. 2013. Refrains for Moving Bodies. Durham and London: Duke University Press.

Noë, Alva. 2013. "Making Worlds Available." In: Knowledge in Motion. Perspectives of Artistic and Scientific Research in Dance, edited by Sabine Gehm et al. Bielefeld: Transcript, 121127.

Quine, W. v. O. “Two dogmas of empiricism.” In The Philosophical Review, Vol. 60 (1951), 20-43.

Rouse, Joseph. 2007. Naturalism and Scientific Practices: A Concluding Scientific Postscript. Wesleyan University.

Royce, Anya Peterson. 2004. Antbropology of the Performing Arts: Artistry, Virtuosity and Interpretation in Cross-Cultural Perspective. Walnut Creek, CA: AltaMira Press. 2002. The Anthropology of dance. 2d ed. Alton, UK: Dance.

Ruby,Jay. 2000. "Researching with a Camera:The Anthropologist as Picture Taker.”In: Picturing Culture. Explorations of Film and Anthropology. Chicago: University of Chicago Press, 4166.

Sansi, Roger. 2014. "Art, Anthropology and the Gift." Forthcoming.

Schechner, Richard. 1985. Between Theater and Anthropology. Philadelphia: University of Pennsylvania Press.

Scheper-Hughes, Nancy \&Lock, Margaret. 1987. "The Mindful Body: A Prolegomenon to Future Work in Medical Anthropology.” In: Medical Anthropology Quarterly, New Series, 
Vol. 1, No. 1 (March 1987), 6-41.

Schneider, Arnd \& Wright, Christopher (eds.). 2013. Anthropology and art practice. London: Bloomsbury.

. 2010. Between Art and Anthropology: Contemporary Ethnographic Practice. Oxford/New York: Berg Publishers, 2010.

Schneider, Rebecca. 2011. Performing remains. Oxon/New York: Routledge.

Steyerl, Hito. "Beginnings: Harun Farocki, 1944-2014." e-flux journal online, retrieved last on 31/03/2015, http://www.e-flux.com/announcements/beginnings-harunfarocki-1944-2014/.

Strathern, Marilyn. 2009. "Using Bodies to Communicate." In: Social Bodies, edited by Helen Lambert and Maryon MacDonald. Oxford/New York: Berghahn Books, 148-169.

Turner, Victor. 1986. The Anthropology of Performance. New York: PAJ Publications.

Date received: 2015-06-01

Date accepted: 2016-01-18 